Article type : Original Article

\title{
Economic evaluation of lupus nephritis in the Systemic Lupus International Collaborating Clinics inception cohort using a multistate model approach
}

Megan R.W. Barber MD, PhD ${ }^{1}$, John G. Hanly $\mathrm{MD}^{2}$, Li Su PhD³ , Murray B. Urowitz MD ${ }^{4}$, Yvan St Pierre MSc ${ }^{5}$, Juanita Romero-Diaz MD, MS ${ }^{6}$, Caroline Gordon MD ${ }^{7}$, Sang-Cheol Bae MD, PhD, $\mathrm{MPH}^{8}$, Sasha Bernatsky MD, $\mathrm{PhD}^{9}$, Daniel J Wallace $\mathrm{MD}^{10}$, David A. Isenberg $\mathrm{MD}^{11}$, Anisur Rahman $\mathrm{PhD}^{11}$, Ellen M. Ginzler MD, MPH ${ }^{12}$, Michelle Petri MD, $\mathrm{MPH}^{13}$, Ian N. Bruce MD ${ }^{14}$, Paul R. Fortin MD, MPH ${ }^{15}$, Dafna D. Gladman MD ${ }^{4}$, Jorge Sanchez-Guerrero MD, $\mathrm{MS}^{4}$, Rosalind Ramsey-Goldman MD, $\mathrm{DrPh}^{16}$, Munther A. Khamashta MD, PhD ${ }^{17}$, Cynthia Aranow $\mathrm{MD}^{18}$, Meggan Mackay MD, $\mathrm{MS}^{18}$, Graciela S. Alarcón MD, MPG ${ }^{19}$, Susan Manzi MD, MPH ${ }^{20}$, Ola Nived MD, $\mathrm{PhD}^{21}$, Andreas Jönsen MD, $\mathrm{PhD}^{21}$, Asad A. Zoma MBChB ${ }^{22}$, Ronald F. van Vollenhoven MD, $\mathrm{PhD}^{23}$, Manuel RamosCasals MD, $\mathrm{PhD}^{24}$, Guillermo Ruiz-Irastorza MD, $\mathrm{PhD}^{25}$, S. Sam Lim MD, MPH ${ }^{26}$, Kenneth C. Kalunian $\mathrm{MD}^{27}$, Murat Inanc $\mathrm{MD}^{28}$, Diane L. Kamen MD, MSCR ${ }^{29}$, Christine A. Peschken $\mathrm{MD}, \mathrm{MSc}^{30}$, Soren Jacobsen MD, DMSc ${ }^{31}$, Anca Askanase MD, MPH ${ }^{32}$, Chris Theriault $\mathrm{BSc}^{33}$, Vernon Farewell $\mathrm{PhD}^{3}$, Ann E. Clarke MD, $\mathrm{MSc}^{34}$

\section{Institutions:}

${ }^{1}$ Department of Medicine, University of Calgary, AB, Canada;

2Division of Rheumatology, Department of Medicine and Department of Pathology, Queen Elizabeth II Health Sciences Centre and Dalhousie University, Halifax, Nova Scotia, Canada;

${ }^{3}$ MRC Biostatistics Unit, University of Cambridge, Cambridge, UK;

${ }^{4}$ Centre for Prognosis Studies in the Rheumatic Diseases, Toronto Western Hospital and University of Toronto, ON, Canada;

${ }^{5}$ Division of Clinical Epidemiology, Research Institute of the McGill University Health Center, Montreal, Canada;

${ }^{6}$ Instituto Nacional de Ciencias Medicas y Nutrición, Mexico City, Mexico;

${ }^{7}$ Rheumatology Research Group, Institute of Inflammation and Ageing, College of Medical and Dental Sciences, University of Birmingham, Birmingham, UK;

This article has been accepted for publication and undergone full peer review but has not been through the copyediting, typesetting, pagination and proofreading process, which may lead to differences between this version and the Version of Record. Please cite this article as doi: 10.1002/acr.23480

This article is protected by copyright. All rights reserved. 
${ }^{8}$ Department of Rheumatology, Hanyang University Hospital for Rheumatic Diseases, Seoul, Korea;

${ }^{9}$ Divisions of Rheumatology and Clinical Epidemiology, McGill University Health Centre;

${ }^{10}$ Cedars-Sinai/David Geffen School of Medicine at UCLA, Los Angeles, CA, USA;

${ }^{11}$ Centre for Rheumatology, Department of Medicine, University College London, UK;

${ }^{12}$ Department of Medicine, SUNY Downstate Medical Center, Brooklyn, NY, USA;

${ }^{13}$ Division of Rheumatology, Johns Hopkins University School of Medicine, Baltimore, MD, USA;

${ }^{14}$ Arthritis Research UK Epidemiology Unit, Institute of Inflammation and Repair, School of Biological Sciences, Faculty of Biology, Medicine and Health, Manchester Academic Health Sciences Centre, The University of Manchester, Manchester, UK; and NIHR Manchester Musculoskeletal Biomedical Research Unit, Central Manchester University Hospitals NHS Foundation Trust, Manchester Academic Health Science Centre;

${ }^{15}$ Division of Rheumatology, CHU de Québec - Université Laval, Quebec City, Canada;

${ }^{16}$ Northwestern University and Feinberg School of Medicine, Chicago, IL, USA;

${ }^{17}$ Lupus Research Unit, The Rayne Institute, St Thomas' Hospital, King's College London School of Medicine, UK, London, UK;

${ }^{18}$ Feinstein Institute for Medical Research, Manhasset, NY, USA;

${ }^{19}$ Division of Clinical Immunology and Rheumatology, Department of Medicine, University of Alabama at Birmingham, Birmingham, AL, USA;

${ }^{20}$ Division of Rheumatology, University of Pittsburgh School of Medicine, Pittsburgh, PA, USA;

${ }^{21}$ Department of Clinical Sciences, Rheumatology, Lund University, Lund, Sweden;

${ }^{22}$ Lanarkshire Centre for Rheumatology, Hairmyres Hospital, East Kilbride, Scotland UK;

${ }^{23}$ Unit for clinical therapy research (ClinTRID), Karolinska Institute, Stockholm, Sweden;

${ }^{24}$ Josep Font Autoimmune Diseases Laboratory, IDIBAPS, Department of Autoimmune Diseases, Hospital Clínic, Barcelona, Spain;

${ }^{25}$ Autoimmune Diseases Research Unit, Department of Internal Medicine, BioCruces Health Research Institute, Hospital Universitario Cruces, University of the Basque Country, Barakaldo, Spain;

${ }^{26}$ Emory University School of Medicine, Division of Rheumatology, Atlanta, Georgia, USA

${ }^{27}$ UCSD School of Medicine, La Jolla, CA, USA;

This article is protected by copyright. All rights reserved. 
${ }^{28}$ Division of Rheumatology, Department of Internal Medicine, Istanbul Medical Faculty, Istanbul University, Istanbul, Turkey;

${ }^{29}$ Medical University of South Carolina, Charleston, South Carolina, USA;

${ }^{30}$ University of Manitoba, Winnipeg, Manitoba, Canada;

${ }^{31}$ Copenhagen Lupus and Vasculitis Clinic, Rigshospitalet, Copenhagen University Hospital, Blegdamsvej 9, 2100, Copenhagen, Denmark;

${ }^{32}$ Hospital for Joint Diseases, NYU, Seligman Centre for Advanced Therapeutics, New York NY;

${ }^{33}$ Department of Medicine, Queen Elizabeth II Health Sciences Centre and Dalhousie University, Halifax, Nova Scotia, Canada;

${ }^{34}$ Division of Rheumatology, University of Calgary, $A B$, Canada;

Corresponding author aeclarke@ucalgary.ca

Division of Rheumatology, Department of Medicine, University of Calgary, HRIC Building, Room 3AA18, 3280 Hospital Drive, Calgary, Alberta T2N 4Z6, Canada. Telephone: 403210 8786

\section{Funding}

The Systemic Lupus International Collaborating Clinics (SLICC) research network received funding for this study from Bristol-Myers Squibb.

John G. Hanly was supported by the Canadian Institutes of Health Research (grant MOP88526).

Drs. Li Su and Vernon Farewell's work was supported by MRC (UK) funding (U105261167).

Dr. Caroline Gordon's work was supported by Lupus UK, Sandwell and West Birmingham Hospitals NHS Trust and the NIHR /Wellcome Trust Clinical Research Facility in Birmingham.

Dr. Sang-Cheol Bae's work was supported in part by an unrestricted grant (Hanyang University 201600000001387).

This article is protected by copyright. All rights reserved. 
The Montreal General Hospital Lupus Clinic is partially supported by the Singer Family Fund for Lupus Research.

Dr. Isenberg and Dr. Rahman are supported by the National Institute for Health Research University College London Hospitals Biomedical Research Centre.

The Hopkins Lupus Cohort is supported by the NIH (grant AR43727).

Dr. Bruce is an NIHR Senior Investigator and is funded by Arthritis Research UK, the National Institute for Health Research Manchester Biomedical Research Unitand the NIHR/Wellcome Trust Manchester Clinical Research Facility. The views expressed in this publication are those of the author(s) and not necessarily those of the NHS, the National Institute for Health Research or the Department of Health.

Dr. Mary Anne Dooley's work was supported by the NIH (grant RR00046).

Dr. Paul R. Fortin holds a tier 1 Canada Research Chair on Systemic Autoimmune Rheumatic Diseases at Université Laval.

Dr. Ramsey-Goldman's work was supported by the NIH (grants 8UL1TR000150 formerly UL-1RR-025741, K24-AR-02318, and P60AR064464 formerly P60-AR-48098).

Dr. Ruiz-Irastorza is supported by the Department of Education, Universities and Research of the Basque Government.

Dr. Soren Jacobsen is supported by the Danish Rheumatism Association (A3865) and Rigshospitalet.

Dr. Clarke holds The Arthritis Society Chair in Rheumatic Diseases at the University of Calgary.

Running Head: Economic Evaluation of Lupus Nephritis in an International Inception Cohort

This article is protected by copyright. All rights reserved. 


\section{Manuscript}

\section{Abstract \\ Objective}

Little is known about the long-term costs of lupus nephritis (LN). These were compared between patients with and without LN based on multistate modelling.

\section{Methods}

Patients from 32 centres in 11 countries were enrolled in the Systemic Lupus International Collaborating Clinics (SLICC) inception cohort within 15 months of diagnosis and provided annual data on renal function, hospitalizations, medications, dialysis, and selected procedures. LN was diagnosed by renal biopsy or the American College of Rheumatology classification criteria. Renal function was assessed annually using estimated glomerular filtration rate (eGFR) or proteinuria (ePrU). A multistate model was used to predict 10-year cumulative costs by multiplying annual costs associated with each renal state by the expected state duration.

\section{Results}

1,545 patients participated, $89.3 \%$ female, mean age at diagnosis 35.2 years (SD 13.4), 49.0\% Caucasian, and mean follow up 6.3 years (SD 3.3). LN developed in $39.4 \%$ by the end of follow up. Ten-year cumulative costs were greater in those with LN and an eGFR < $30 \mathrm{ml} / \mathrm{min}$ ( $\$ 3105792015$ Canadian dollars versus $\$ 19987$ if no LN and eGFR > $60 \mathrm{ml} / \mathrm{min}$ ) or with LN and ePrU > $3 \mathrm{~g} / \mathrm{d}$ ( $\$ 84040$ versus $\$ 20499$ if no $L N$ and ePrU $<0.25 \mathrm{~g} / \mathrm{d}$ ).

\section{Conclusion}

This article is protected by copyright. All rights reserved. 
Patients with eGFR $<30 \mathrm{ml} / \mathrm{min}$ incurred 10 -year costs 15 -fold higher than those with normal eGFR. By estimating the expected duration in each renal state and incorporating associated annual costs, disease severity at presentation can be used to anticipate future healthcare costs. This is critical knowledge for cost-effectiveness evaluations of novel therapies.

\section{Significance and Innovations}

- We are providing the first estimates of annual and 5 and 10-year cumulative costs stratified by baseline renal function in an international, multi-ethnic inception SLE cohort.

- An inception cohort allows for the development of multistate modeling, which provides a dynamic representation of both improvement and deterioration of renal disease in continuous time.

- Patients with lupus nephritis and a baseline eGFR $<30 \mathrm{ml} / \mathrm{min}$ incurred tenyear costs of $\$ 310579$ (2015 Canadian dollars) versus $\$ 19987$ if they did not have lupus nephritis and their baseline eGFR was $>60 \mathrm{ml} / \mathrm{min}$.

- Similarly, patients with lupus nephritis and a baseline ePrU $>3 \mathrm{~g} / \mathrm{d}$ incurred ten-year costs of $\$ 84040$ (2015 Canadian dollars) versus $\$ 20499$ if they did not have lupus nephritis and their baseline ePrU was $<0.25 \mathrm{~g} / \mathrm{d}$.

This article is protected by copyright. All rights reserved. 


\section{Introduction}

Renal disease in SLE patients is associated with significant morbidity and mortality, and is extremely costly (1). Approximately $40 \%$ of SLE patients develop lupus nephritis (LN), although in African descendants and Hispanics of predominantly Amerindian ancestry the frequency may be as high as $60 \%(2-4)$. Lupus nephritis varies from clinically silent pathology to end-stage renal disease (ESRD), and is often present at the time of SLE diagnosis (2). The current standard of care includes induction with corticosteroids and mycophenolate mofetil, cyclophosphamide, or rituximab and long-term maintenance therapy with mycophenolate mofetil or azathioprine $(5,6)$. Despite receiving treatment according to established guidelines, a significant proportion of patients still progress to ESRD, requiring dialysis or transplantation. Recent studies including a 30-year single centre study (7) indicate that the 5-year risk of ESRD in SLE patients with renal disease ranges between $6.9 \%$ to $8.1 \%$ and a meta-analysis (8) reports that the 5-year risk of ESRD in those with LN decreased from $16 \%$ in the 1970 s to $11 \%$ in the mid-1990s. These rates have plateaued for at least the past two decades. The presence of renal damage is the most important predictor of early mortality in SLE patients (9); in fact, it has been shown that renal damage reduces the survival of SLE patients by approximately 24 years, compared to the general population (10) and LN patients who develop ESRD have a 26-fold increased risk of mortality (11). Hence, numerous studies demonstrate significantly higher costs in patients with LN versus those without LN (1,12-14).

While SLE patients with renal injury are known to have increased healthcare costs compared to those without renal involvement (15), there is very little data on the long-term healthcare costs of LN patients (12). Between 1999 and 2011, the Systemic Lupus International Collaborating Clinics (SLICC) enrolled patients into an inception cohort to study long-term clinical outcomes. In previous research on this cohort, reversible multistate modeling has

This article is protected by copyright. All rights reserved. 
been used to estimate transitions (improvement or deterioration) between multiple states of renal function (16). This type of modeling is unique in that it provides a dynamic representation of renal dysfunction in continuous time as opposed to the typical static crosssectional view provided by conventional regression analyses. In the current study, multistate modeling was used to forecast the duration in each renal state and the annual direct costs associated with each renal state were calculated. Five and ten-year cumulative costs were then estimated by multiplying the annual costs associated with each renal state with the expected duration in that state and were compared between patients with and without renal involvement. This methodology allows for prediction of costs for renal states in which there are few observations.

Understanding how patients progress through states of renal disease and the costs associated with each state will allow for cost-effectiveness analyses of novel emerging therapies.

\section{Patients and Methods}

Inception cohort

The SLICC network includes 32 academic centres from 11 countries (17). Members of this network enrolled patients fulfilling the American College of Rheumatology (ACR) revised classification criteria for SLE (18) into an inception cohort within 15 months of SLE diagnosis (i.e., date at which criteria were met). For this study, data collection extended from 1999 through to 2013. Data were collected at enrollment on demographics (age, sex, race/ethnicity) and at enrollment and annually ( \pm 6 months) on disease activity [SLE Disease Activity Index - 2000 (SLEDAI-2K) (19)], disease damage [SLICC/ ACR Damage Index (SDI) (20)], smoking history, and alcohol consumption [high risk consumption defined as

This article is protected by copyright. All rights reserved. 
greater than 10 units per week for females and 15 units per week for males (21)]. Data were also collected annually on all hospitalizations, medications (including corticosteroids, antimalarials, immunosuppressives, biologics, antihypertensives, lipid-lowering agents, antiepileptics, anti-psychotics and other psychoactive drugs, anticoagulants, and antiplatelets), and dialysis from any time since the previous assessment. The initial focus of the inception cohort was on cardiovascular and neuropsychiatric outcomes and later, on renal outcomes, and as part of the data collection protocol, diagnostic procedures related only to these outcomes were also recorded (e.g. ECGs, echocardiograms, stress tests, neuroimaging, and renal biopsies) and used for resource use and cost estimation. The study was approved by the institutional research ethics review board at each site and each participant provided written informed consent.

\section{Renal status}

Lupus nephritis was diagnosed by renal biopsy or fulfillment of the renal item on the ACR classification criteria for SLE (18).

Renal function was also assessed annually based on estimated glomerular filtration rate (eGFR) using the Modification of Diet in Renal Disease (MDRD) equation (22), or on estimated proteinuria (ePrU) as measured by either 24 hour urine collection or spot urine total protein to creatinine ratio (23). eGFR was divided into three states: state 1 (eGFR > 60 $\mathrm{ml} / \mathrm{min}$ ), state 2 (eGFR $30-60 \mathrm{ml} / \mathrm{min}$ ) and state 3 (eGFR $<30 \mathrm{ml} / \mathrm{min}$ ). ePrU was stratified as: state $1(e P r U<0.25 \mathrm{~g} / \mathrm{d})$, state $2(e P r U ~ 0.25-3 \mathrm{~g} / \mathrm{d})$, or state $3(e P r U>3 g / d)$. End stage renal disease (ESRD) was identified based on the SDI renal variable (20).

\section{Statistical Analysis}

This article is protected by copyright. All rights reserved. 


\section{Multistate Modelling}

At each assessment, patients were assessed for the presence of LN and state of eGFR and ePrU and were assigned to one of six states in Markov models (Figure 1) for either eGFR or ePrU. Within the eGFR model, it was clinically sensible to assume that a patient could not move from an eGFR state 1 or 2 to ESRD without first having transitioned through eGFR state 3 with LN. However, within the ePrU model, it was clinically reasonable to assume that a patient could develop ESRD from any ePrU state with LN. Further, in both models, direct transition from one state to a non-adjacent state was not permitted in continuous time (except for transition of ePrU state 1 or state 2 with LN to ESRD) and transitions could occur into adjacent higher or lower states, except for ESRD or LN where the transitions were unidirectional. However, changes between non-adjacent states could be observed between assessments, with the transition being assumed to occur through a set of adjacent transitions. Death was regarded as a censoring event consistent with the collection of cost data only in years when death did not occur.

Due to small numbers of transitions into less frequent states, the transition rates between observed states were estimated with a null multistate model without explanatory variables [full details provided in (16)]. This model can account for intermittent observations and, through conditioning on current states, for the correlation between observations within the same patient. The correlation among the states of a patient at the different assessment visits was characterized through the Markov assumption that the future evolution of a patient's renal function depends only on his/her current state and not on his/her previous history. Transition rates were estimated through maximum likelihood estimation and expected state occupancy times over fixed follow-up periods were also obtained.

\section{Calculating costs}

This article is protected by copyright. All rights reserved. 
Costs included all hospitalizations, medications, dialysis, and diagnostic procedures related to cardiovascular, neuropsychiatric, and renal manifestations. Costs were calculated from the Canadian national health insurance perspective by multiplying each health resource by its corresponding Canadian unit cost at the 2015 price level. Except for hospitalizations, national estimates for unit costs were based on provincial price data from the Ontario and Quebec Ministries of Health, adjusted to reflect average Canadian prices. The unit cost for medications was sourced from the Quebec List of Medications (published by the Régie de l'assurance maladie du Québec). Reimbursement for physician services related to investigations, dialysis and other procedures was based on the Ontario fee schedule (published by the Ontario Health Insurance Plan), and hospital costs for dialysis and day procedures were sourced from the Ontario Case Costing Initiative (OCCI) (24). Costs for hospitalizations were developed through the Case-Mix Group method from the Canadian Institute for Health Information (CIHI). This methodology adjusts for the case complexity through resource intensity weights. Appropriate weights were identified using data from previous research on reasons for hospitalizations in a representative sample of lupus patients (25). Cost per in-patient day was derived from this data, which also incorporated physician reimbursements during hospital stays, based on fee schedules from Ontario and Quebec. Adjustment to average Canadian 2015 price levels was done, in the case of medications, using the Consumer Price Index (http://www.statcan.gc.ca/tablestableaux/sum-som/101/cst01/econ09a-eng.htm) ratio of provincial to national price indices for prescribed medicines, and for all other health services, using similar wage ratios for labour in the healthcare sector across provinces and calendar years (http://www.statcan.gc.ca/tablestableaux/sum-som/l01/cst01/health23-eng.htm).

To compute estimates of 5 and 10-year cumulative costs, annual costs associated with each state of renal function, defined as presence of LN and state of eGFR or ePrU or ESRD, were first estimated. Generalized least squares regression modeling with random effects was

This article is protected by copyright. All rights reserved. 
used to account for possible confounding of the relationship between annual costs and state of renal function. Potential confounding covariates included age, sex, race/ethnicity, geographic region (i.e. within versus outside of North America), disease duration, smoking, and high-risk alcohol use. Adjusted annual cost estimates were predicted using the average values of relevant confounders, and confidence intervals $(\mathrm{Cl})$ were calculated using the bootstrapping method, accounting for the non-normal distribution of healthcare costs. Five and ten-year cumulative costs stratified by baseline renal state were calculated by multiplying the adjusted annual cost estimates associated with each renal state by the expected duration in each state over five and ten years. However, accurate discounting of future costs required this calculation to be done for each consecutive year, using expected duration over one-year and repeating the process for longer term estimates. The year-toyear change in state was approximated using transition probabilities estimated after one year. The one-year state durations and transition probabilities were both derived from multistate modelling (16). Future annual costs for each baseline renal state were discounted at a yearly rate of $3 \%$ and annual costs were summed over the five-or-ten year period. Note that since the null multistate model does not include adjustment variables, predicted long-term costs can be compared based on this model, but will only reflect partial adjustment for confounders.

\section{Results}

\section{Patients}

A total of 1826 patients were recruited from 32 SLICC centres in 11 countries. Of these, 1545 patients (United States, $n=426$; Europe, $n=405$; Canada, $n=372$; Mexico, $n=184$; and Korea, $n=158$ ) (Table 1) had at least an enrollment and one follow up assessment, allowing for costing analysis, and were therefore included in the analysis. Patients were $89.3 \%$ female, with a mean age at diagnosis of 35.2 years (SD 13.4), mean disease duration at

This article is protected by copyright. All rights reserved. 
enrollment of 0.47 years (SD 0.35), and mean follow up of 6.3 years (SD 3.3) (range: 0.6 to 13.7 years); $49.0 \%$ of the patients were Caucasian. These characteristics are similar to those for the entire cohort (2).

Renal status

Lupus nephritis was diagnosed in 609/1545 patients (39.4\%). It was present at enrollment in $466 / 1545$ patients $(30.2 \%)$ and developed during follow up in another $143 / 1545$ patients $(9.3 \%)$.

\section{Annual costs and predictors}

For the eGFR model examining the association between annual costs and state of renal function, age greater than 65 years [regression coefficient $\$ 1700$ (95\% CI \$8, \$3392)] and region outside of North America [regression coefficient $\$ 1183$ (95\% Cl \$409, \$1956)] were associated with higher annual costs and Caucasian race/ethnicity [regression coefficient $\$ 870(95 \% \mathrm{Cl}-\$ 1653,-\$ 88)]$ was associated with lower costs. For the ePrU model, the same variables were associated with annual costs [age $>65$ years: regression coefficient \$2229 (95\% CI \$601, \$3858), region outside of North America regression coefficient $\$ 1110$ (95\% Cl \$337, \$1884) and Caucasian race/ethnicity regression coefficient $-\$ 789(95 \% \mathrm{Cl}$ \$1573, \$-4)].

Once adjusted accordingly, i.e., calculated at cohort average values (in this case, the observed proportions of patients older than 65 years, residing outside of North America, and of Caucasian race/ethnicity in the sample), annual costs by renal state were markedly higher in those with ESRD than in those without LN and eGFR $>60 \mathrm{ml} / \mathrm{min}$ (state 1, no LN) or ePrU

This article is protected by copyright. All rights reserved. 
$<0.25 \mathrm{~g} / \mathrm{d}$ (state 1, no LN) [(\$51313 (95\% Cl \$38 645, \$63 982) versus $\$ 1813(95 \% \mathrm{Cl}$

\$1034, \$2593) versus \$1797 (95\% CI \$995, \$2599)] (Table 2).

Annual unadjusted component costs are provided in Supplementary Table 1. In patients without LN, medications were the most costly component, whereas in those patients with LN and eGFR $<30 \mathrm{ml} / \mathrm{min}$ or with ESRD, dialysis was the most costly component. In patients with ePrU $0.25 \mathrm{~g} / \mathrm{d}$ or more, with or without LN, hospitalization was the most costly component. In all other renal states, medications were the most costly component.

\section{Transition probabilities and expected state durations}

Based on the estimated transition rates between states, the probability and expected duration for each state of eGFR and ePrU in the absence and presence of LN after 1 year is shown in Table 3. As anticipated, for example, patients with $L N$ and a baseline eGFR $>60$ $\mathrm{ml} / \mathrm{min}$ (state $1, \mathrm{LN}$ ) had a much lower probability of transitioning to ESRD $(0.1 \%)$ than those with LN and a baseline eGFR $<30 \mathrm{ml} / \mathrm{min}$ (state 3, LN) (37.6\%). Accordingly, patients with $\mathrm{LN}$ and an eGFR $>60 \mathrm{~mL} / \mathrm{min}$ (state $1, \mathrm{LN}$ ) were forecasted to spend none of the next year in ESRD, whereas patients with $\mathrm{LN}$ and an eGFR $<30 \mathrm{~mL} / \mathrm{min}$ (state 3, $\mathrm{LN}$ ) were forecasted to spend one fifth of the next year in ESRD (Table 3). Transition probabilities after 1 year and expected state durations over 1 year are also shown for ePrU in Table 3.

\section{Five and ten-year cumulative costs}

Five-year cumulative costs were predicted to be substantially higher in patients with LN and an eGFR $<30 \mathrm{~mL} / \mathrm{min}$ (state 3, LN) or with ESRD at baseline (Table 4). Patients with LN and an eGFR $<30 \mathrm{~mL} / \mathrm{min}$ (state 3, LN) had 5-year cumulative costs of $\$ 154320(95 \% \mathrm{Cl}$

This article is protected by copyright. All rights reserved. 
\$100 919, \$207 721) and those with ESRD had costs of \$242 196 (95\% Cl \$182 407, \$301 985) while those without $L N$ and eGFR $>60 \mathrm{~mL} / \mathrm{min}$ (state 1, no LN) at baseline were expected to accrue 5-year cumulative costs of $\$ 9536$ (95\% Cl $\$ 5246, \$ 13825)$ (Table 4).

Ten-year cumulative costs were also greater in those with $L N$ and an eGFR $<30 \mathrm{~mL} / \mathrm{min}$ (state 3, LN) or with ESRD at baseline. Patients with LN and an eGFR $<30 \mathrm{~mL} / \mathrm{min}$ (state 3, LN) had 10-year cumulative costs of $\$ 310579$ (95\% CI $\$ 217631, \$ 403528)$ and those with ESRD had costs of $\$ 451406$ (95\% CI $\$ 339$ 977, \$562 835) while those without LN and eGFR > $60 \mathrm{~mL} / \mathrm{min}$ (state 1, no LN) at baseline had 10-year cumulative costs of only $\$ 19$ 987 (95\%Cl \$11 061, \$28 913) (Table 4).

Similarly, when renal function was stratified by ePrU, five-year cumulative costs were highest in those with LN and an ePrU of $>3 \mathrm{~g} / \mathrm{d}$ (state $3, \mathrm{LN}$ ) or with ESRD at baseline. Patients with $\mathrm{LN}$ and an ePrU of $>3 \mathrm{~g} / \mathrm{d}$ (state 3, LN) had 5-year cumulative costs of $\$ 39638$ (95\% C1 $\$ 27$ 834, $\$ 51441$ ) while those without $L N$ and ePrU of $<0.25 \mathrm{~g} / \mathrm{d}$ (state 1 , no $\mathrm{LN}$ ) at baseline had 5-year cumulative costs of only $\$ 9651$ (95\% Cl $\$ 5393,13$ 909) (Table 4). Ten-year cumulative costs were also greater in those with LN and an ePrU of $>3 \mathrm{~g} / \mathrm{d}$ (state $3, \mathrm{LN}$ ) or with ESRD at baseline (Table 4).

\section{Discussion}

We have provided the first comparison of annual and 5 and 10-year cumulative costs stratified by baseline renal function in an international, multi-ethnic inception cohort of SLE patients. The use of an inception cohort allows for the development of multistate modeling, which can be used to forecast expected duration in each renal state. By incorporating annual costs associated with each renal state, long-term cumulative costs can be estimated

This article is protected by copyright. All rights reserved. 
stratified by baseline renal status. The regression model examining the association between annual costs and state of renal function produced point estimates of higher annual costs by an average of $\$ 870$ in non-Caucasians compared to Caucasians in the eGFR model and an average of $\$ 789$ in the ePrU model, consistent with literature on poorer health outcomes in non-Caucasians (26). As anticipated, worsening renal disease resulted in higher healthcare costs, with patients with ESRD projected to incur 10-year cumulative costs almost 23-fold that of patients with no LN and normal eGFR [(\$451 406 (95\% CI \$339 977, \$562 835) versus $\$ 19987$ (95\% Cl \$11 061, \$28 913)]. Even patients with LN with eGFR < $60 \mathrm{ml} / \mathrm{min}$ who did not have ESRD still incurred substantial costs $[(\$ 111326$ (95\% CI \$76 466, \$146 $185)$ to $\$ 310579$ (95\% Cl $\$ 217631, \$ 403528)$ ]. Patients with an eGFR $<30 \mathrm{ml} / \mathrm{min}$ and LN are substantially more expensive than patients with ePrU $>3 \mathrm{~g} / \mathrm{L}$ and LN (10-year costs of $\$ 310579$ versus $\$ 84040$ ), because the former represent a sicker group of patients.

However, our study has some limitations. The SLICC network is based within tertiary care academic centres and therefore our patient population may not represent the entire spectrum of SLE patients and likely overestimates the hospitalization, medication, and dialysis costs incurred by SLE patients in a community practice. Further, we did not capture indirect costs due to lost productivity in paid and unpaid endeavors. Additionally, our assessment of healthcare resource utilization was incomplete and therefore we have underestimated total direct costs. While we did capture the most costly components of health resource use - hospitalizations, medications, dialysis, and physician visits associated with these services, we did not collect data on other physician or emergency room visits and our assessment of diagnostic procedures was restricted to those related to cardiovascular, neuropsychiatric, and renal disease. Based on our previous work (27) estimating long-term costs for Canadian lupus patients, where all components of direct costs were included, our current estimates would represent, on average, $68 \%$ of total direct costs. Our costs were also based only on data that was recorded while patients survived and incurred costs for the whole period preceding questionnaire administration. There were 36 deaths in the study

This article is protected by copyright. All rights reserved. 
(Supplemental Table 2) and because of our study design, we have no data on resource use in the year preceding death.

The substantial cost of LN has been reported by others, primarily through the use of insurance claims databases. Studies from the US have shown that patients with LN incurred annual costs that are 2.5 to 6 -fold higher than patients without LN $(1,12-14)$. Carls et al. reported annual costs were almost 4-fold higher in US patients with LN [\$83 869 versus $\$ 22$ 188 in those without LN] ${ }^{1}$ (1) while Furst et al. reported that patients with LN incurred annual costs of $\$ 44524$ versus $\$ 7113$ in matched controls without SLE (14). A Medicaid study reported lower annual costs, but the differential between those with $L N$ and matched controls without SLE was almost 3-fold [\$38 401 versus \$12 945] (12). These annual costs for patients with LN are substantially higher than our estimates, which range between $\$ 3858$ and \$20 837 depending on the eGFR. However, our cost estimates for ESRD of \$ 51313 are more comparable to the estimates for LN based on insurance data. It is to be expected that our estimates are lower as we did not include all healthcare resources and we used Canadian prices for healthcare, which are much lower than in the US, relative to other consumer goods.

However, use of insurance claims data is limited by reliance on diagnostic codes, which may lead to inclusion of patients who do not have $L N$, and the lack of detailed data on renal pathology and renal function. Other studies have employed self-reported healthcare utilization in a clinical cohort to estimate the direct costs associated with LN (15), demonstrating almost 5-fold higher costs in ESRD patients compared to SLE patients without any renal damage as defined on the SDI (\$144 389 versus $\$ 29499$ ). In our current study, we observed an over 25-fold difference in 5-year costs between those with ESRD and an eGFR > $60 \mathrm{ml} / \mathrm{min}$ and no LN (\$242 196 versus \$9536). This much higher differential in

This article is protected by copyright. All rights reserved. 
our current study is attributable to two factors: 1) the costs of ESRD are higher in the current study because they are more precise and 2) the costs incurred by patients without renal damage as defined by the SDI are higher than in our current study because these patients were older, had accrued more non-renal damage, and also had renal dysfunction not sufficient to fulfill the SDI renal criteria.

A recent Swedish study estimated both the annual direct and indirect costs of LN compared to all SLE patients by linking well-defined clinical cohorts to national registries and the social insurance system. SLE patients with LN incurred direct costs of $\$ 18579$ compared to $\$ 13$ 339 in all SLE patients (28), with indirect costs comprising approximately $60 \%$ of total costs for those with $L N$ and $70 \%$ for those without $L N$. These direct cost estimates for patients with LN are reasonably comparable to ours where annual costs ranged between $\$ 3858$ and \$20 837 for those with LN, but without ESRD.

Unfortunately, the frequency and survival of SLE-related ESRD has not improved over several decades $(7,8,29,30)$, highlighting the need for new therapies. Although numerous clinical trials of biologics have yielded disappointing results for $L N$, novel agents continue to emerge, and there is optimism that some will be proven effective (31). Koutsokeras and Healy $(32,33)$ forecasted the LN market to be $\$ 505$ million by 2022 for seven major international markets (United States, France, Germany, Italy, Spain, the United Kingdom, and Japan). As novel biologics become available, understanding the current costs of LN using standard of care is necessary for cost-effectiveness studies. Biologics are very costly, and are often utilized for only refractory or advanced disease. However, they are likely to become more cost-effective over time as their patents expire while the cost of dialysis is unlikely to decrease. Our study demonstrates the substantial cost increases in patients with

This article is protected by copyright. All rights reserved. 
more advanced renal disease, highlighting the cost savings potentially achieved by earlier aggressive therapy to prevent progression or induce remission of renal disease.

\section{Footnote}

${ }^{1}$ Currencies from publications have been converted to 2015 Canadian dollars

using purchasing power parities data from the Organisation for Economic Cooperation

and Development (https://data.oecd.org/conversion/purchasing-power-parities-

ppp.htm) and the consumer price index from Statistics Canada

(http://www.statcan.gc.ca/tables-tableaux/sum-som/l01/cst01/econ09a-eng.htm).

\section{References}

1. Carls G, Li T, Panopalis P, Wang S, Mell AG, Gibson TB, et al. Direct and indirect costs to employers of patients with systemic lupus erythematosus with and without nephritis. J Occup Environ Med 2009;51:66-79.

2. Hanly JG, O'Keeffe AG, Su L, Urowitz MB, Romero-Diaz J, Gordon C, et al. The frequency and outcome of lupus nephritis: results from an international inception cohort study. Rheumatology 2016;55:252-262.

3. Alarcón GS, Friedman AW, Straaton K V, Moulds JM, Lisse J, Bastian HM, et al. Systemic lupus erythematosus in three ethnic groups: III. A comparison of characteristics early in the natural history of the LUMINA cohort. LUpus in Mlnority populations: NAture vs. Nurture. Lupus 1999;8:197-209.

4. Pons-Estel BA, Catoggio LJ, Cardiel MH, Soriano ER, Gentiletti S, Villa AR, et al. The GLADEL Multinational Latin American Prospective Inception Cohort of 1,214 Patients With Systemic Lupus Erythematosus. Medicine (Baltimore) 2004;83:1-17.

5. Bertsias GK, Tektonidou M, Amoura Z, Aringer M, Bajema I, Berden JHM, et al. Joint European League Against Rheumatism and European Renal Association-European Dialysis and Transplant Association (EULAR/ERA-EDTA) recommendations for the management of adult and paediatric lupus nephritis. Ann Rheum Dis 2012;71:1771-1782.

6. Hahn BH, McMahon MA, Wilkinson A, Wallace WD, Daikh DI, FitzGerald JD, et al. American College of Rheumatology guidelines for screening, treatment, and management of

This article is protected by copyright. All rights reserved. 
lupus nephritis. Arthritis Care Res (Hoboken) 2012;64:797-808.

7. Croca SC, Rodrigues T, Isenberg DA. Assessment of a lupus nephritis cohort over a 30year period. Rheumatology 2011;50:1424-1430.

8. Tektonidou MG, Dasgupta A, Ward MM. Risk of End-Stage Renal Disease in Patients With Lupus Nephritis, 1971-2015: A Systematic Review and Bayesian Meta-Analysis. Arthritis Rheumatol 2016;68:1432-1441.

9. Danila MI, Pons-Estel GJ, Zhang J, Vila LM, Reveille JD, Alarcon GS. Renal damage is the most important predictor of mortality within the damage index: data from LUMINA LXIV, a multiethnic US cohort. Rheumatology 2008;48:542-545.

10. Mok CC, Kwok RCL, Yip PSF. Effect of Renal Disease on the Standardized Mortality Ratio and Life Expectancy of Patients With Systemic Lupus Erythematosus. Arthritis Rheum 2013;65:2154-2160.

11. Yap DYH, Tang CSO, Ma MKM, Lam MF, Chan TM. Survival analysis and causes of mortality in patients with lupus nephritis. Nephrol Dial Transplant 2012;27:3248-3254.

12. Li T, Carls GS, Panopalis P, Wang S, Gibson TB, Goetzel RZ. Long-term medical costs and resource utilization in systemic lupus erythematosus and lupus nephritis: a five-year analysis of a large medicaid population. Arthritis Rheum 2009;61:755-763.

13. Pelletier EM, Ogale S, Yu E, Brunetta P, Garg J. Economic outcomes in patients diagnosed with systemic lupus erythematosus with versus without nephritis: results from an analysis of data from a US claims database. Clin Ther 2009;31:2653-2664.

14. Furst DE, Clarke A, Fernandes AW, Bancroft T, Gajria K, Greth W, et al. Medical costs and healthcare resource use in patients with lupus nephritis and neuropsychiatric lupus in an insured population. J Med Econ 2013;16:500-509.

15. Clarke AE, Panopalis $P$, Petri M, Manzi S, Isenberg DA, Gordon C, et al. SLE patients with renal damage incur higher health care costs. Rheumatology (Oxford) 2008;47:329-333.

16. Hanly JG, Su L, Urowitz MB, Romero-Diaz J, Gordon C, Bae S-C, et al. A Longitudinal Analysis of Outcomes of Lupus Nephritis in an International Inception Cohort Using a Multistate Model Approach. Arthritis Rheumatol (Hoboken, NJ) 2016.

17. Isenberg D, Ramsey-Goldman R, SLICC Group. Systemic Lupus International Collaborating Group--onwards and upwards? Lupus 2006;15:606-7.

18. Hochberg MC. Updating the American College of Rheumatology revised criteria for the classification of systemic lupus erythematosus. Arthritis Rheum 1997;40:1725.

19. Bombardier C, Gladman DD, Urowitz MB, Caron D, Chang CH. Derivation of the SLEDAI. A disease activity index for lupus patients. The Committee on Prognosis Studies in SLE. Arthritis Rheum 1992;35:630-40.

20. Gladman D, Ginzler E, Goldsmith C, Fortin P, Liang M, Sanchez-Guerrero J, et al. The development and initial validation of the systemic lupus international collaborating clinics/American college of rheumatology damage index for systemic lupus erythematosus.

This article is protected by copyright. All rights reserved. 
Arthritis Rheum 1996;39:363-369.

21. Butt $P$, Beirness D, Gliksman L, Paradis C, Stockwell T. Alcohol and health in Canada: $A$ summary of evidence and guidelines for low-risk drinking. Ottawa, Ontario; 2011. Available at: http://www.ccsa.ca/Resource\%20Library/2011-Summary-of-Evidence-and-Guidelines-forLow-Risk\%20Drinking-en.pdf

22. Patel S, Korbet S, Lewis $\mathrm{E}$. The prognosis of severe lupus nephritis based on the Modification of Diet in Renal Disease (MDRD) Study estimated glomerular filtration rate. Lupus 2011;20:256-264.

23. Christopher-Stine L, Petri M, Astor BC, Fine D. Urine protein-to-creatinine ratio is a reliable measure of proteinuria in lupus nephritis. J Rheumatol 2004;31:1557-9.

24. Aghdassi E, Zhang W, St-Pierre Y, Clarke AE, Morrison S, Peeva V, et al. Healthcare cost and loss of productivity in a Canadian population of patients with and without lupus nephritis. J Rheumatol 2011;38:658-66.

25. Clarke AE, Petri MA, Manzi S, Isenberg DA, Gordon C, Senecal JL, et al. An international perspective on the well being and health care costs for patients with systemic lupus erythematosus. Tri-Nation Study Group. J Rheumatol 1999;26:1500-1511.

26. Carter EE, Barr SG, Clarke AE. The global burden of SLE: prevalence, health disparities and socioeconomic impact. Nat Rev Rheumatol 2016;12:605-620.

27. Clarke AE, Petri M, Manzi S, Isenberg DA, Gordon C, Senecal JL, et al. The systemic lupus erythematosus Tri-nation Study: absence of a link between health resource use and health outcome. Rheumatology (Oxford) 2004;43:1016-1024.

28. Jönsen A, Hjalte F, Willim M, Carlsson KS, Sjöwall C, Svenungsson E, et al. Direct and indirect costs for systemic lupus erythematosus in Sweden. A nationwide health economic study based on five defined cohorts. Semin Arthritis Rheum 2016;45:684-690.

29. Costenbader KH, Desai A, Alarcón GS, Hiraki LT, Shaykevich T, Brookhart MA, et al. Trends in the incidence, demographics, and outcomes of end-stage renal disease due to lupus nephritis in the US from 1995 to 2006. Arthritis Rheum 2011;63:1681-1688.

30. Ward MM. Changes in the incidence of endstage renal disease due to lupus nephritis in the United States, 1996-2004. J Rheumatol 2009;36:63-67.

31. Venuturupalli S. Rethinking biologics in lupus nephritis. Lupus 2016;25:1102-1110.

32. Koutsokeras T, Healy T. PharmaPoint: Systemic Lupus Erythematosus and Lupus Nephritis - Global Drug Forecast and Market Analysis to 2022 I Pharmaceuticals and Healthcare I Report Store I GlobalData. Glob Drug Forecast Mark Anal 2013:1-315. Available at: http://store.globaldata.com/market-reports/pharmaceuticals-andhealthcare/pharmapoint-systemic-lupus-erythematosus-and-lupus-nephritis-global-drugforecast-and-market-analysis-to-2022. Accessed December 21, 2016.

33. Koutsokeras T, Healy T. Systemic lupus erythematosus and lupus nephritis. Nat Rev Drug Discov 2014;13:173-174.

This article is protected by copyright. All rights reserved. 

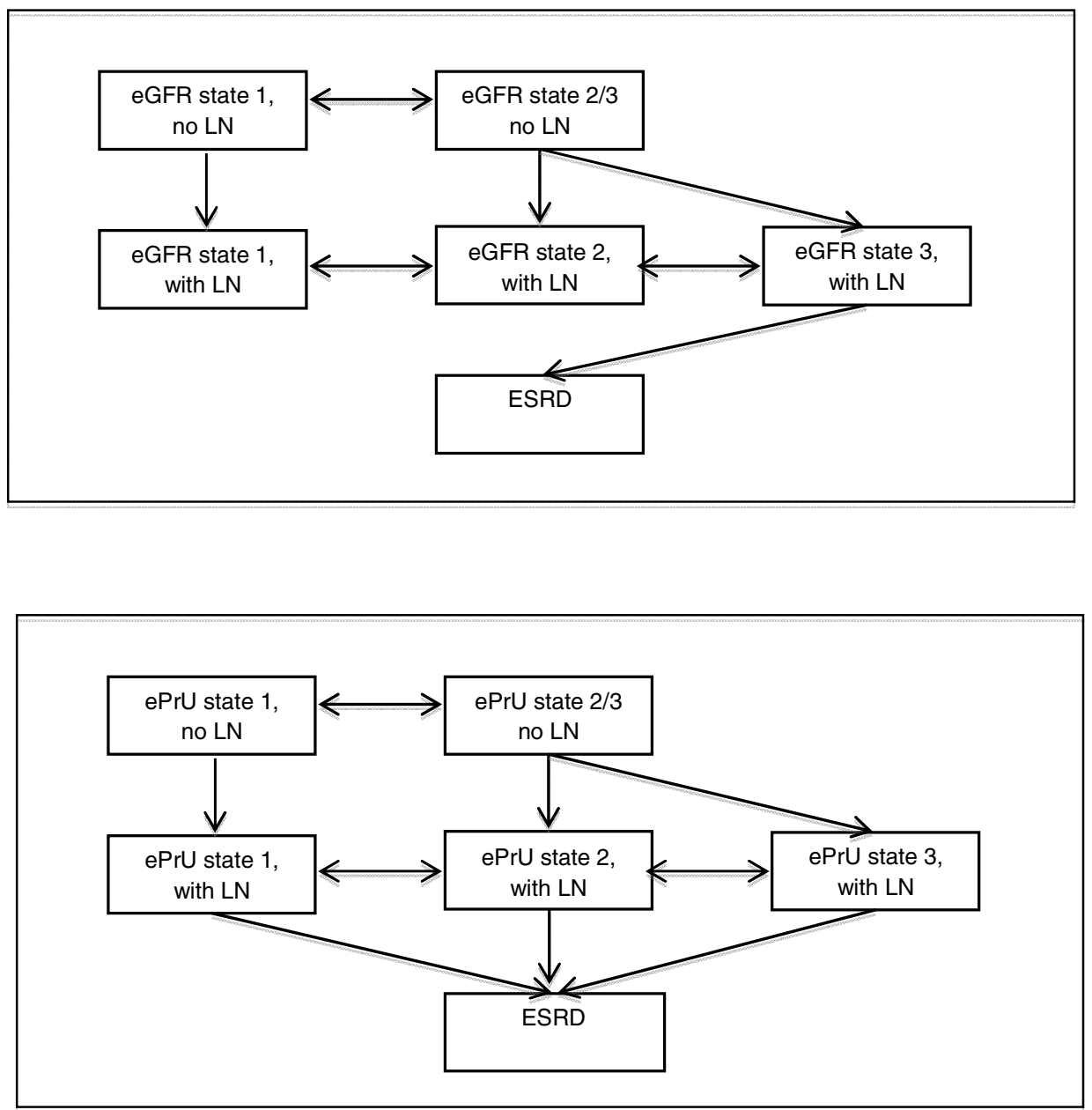

Figure 1: Multstate Markov model for observed transitions between estimated glomerular filtration rate (eGFR) and estimated proteinuria (ePrU) states

eGFR: state $1>60 \mathrm{~mL} / \mathrm{min}$, state $230-60 \mathrm{~mL} / \mathrm{min}$, state $3<30 \mathrm{~mL} / \mathrm{min}$

ePrU: state $1<0.25 \mathrm{~g} / \mathrm{d}$, state $20.25-3.0 \mathrm{~g} / \mathrm{d}$, state $3>3.0 \mathrm{~g} / \mathrm{d}$

This article is protected by copyright. All rights reserved. 


\section{Tables}

Table 1 - Baseline demographic and clinical manifestations of patients

No. of patients:

1545

Age (years): (Mean $\pm S D)$

$35.2(13.4)$

Gender (\%):

Female

89.3

Male

10.7

Race/Ethnicity (\%):

$\begin{array}{lr}\text { Caucasian } & 49.0 \\ \text { Hispanic } & 14.9 \\ \text { Asian } & 16.1 \\ \text { African } & 16.2 \\ \text { Other } & \end{array}$

Country (\%):

$\begin{array}{lc}\text { United States } & 27.6 \\ \text { Europe } & 26.2 \\ \text { Canada } & 24.1 \\ \text { Mexico } & 11.9 \\ \text { Korea } & \end{array}$

ACR Classification Criteria (\%):

Malar Rash

34.7

This article is protected by copyright. All rights reserved. 
Discoid Rash

Photosensitivity

Oral/nasopharyngeal Ulcers

Serositis

Arthritis

Renal Disorder

Neurological Disorder

Hematologic Disorder

Immunologic Disorder

Antinuclear Antibody

SLEDAI-2K $($ Mean \pm SD)

$5.3(5.3)$

SDI score $($ Mean $\pm S D)$ *

Medications (\%):

Corticosteroids

70.3

Antimalarials

67.3

Immunosuppressants

Comorbidities/Lifestyle

Current Smoker (\%)

14.7

Alcohol (\% with high risk consumption)

This article is protected by copyright. All rights reserved. 
$\mathrm{ACR}=$ American College of Rheumatology; SDI = SLICC/ACR Damage index; SLEDAI-2K = SLE Disease

Activity Index - 2000

* For patients with a disease duration of less than six months, SDI cannot be calculated - therefore at enrolment, SDI was available on 580 patients

This article is protected by copyright. All rights reserved. 
Table 2 - Predicted annual health costs stratified by state of eGFR and ePrU

\begin{tabular}{|c|c|c|}
\hline & eGFR & ePrU \\
\hline eGFR/ePrU State* & $\begin{array}{c}\text { Costs, } 2015 \text { CDN\$ } \\
\text { (Mean, 95\% Cl) }\end{array}$ & $\begin{array}{l}\text { Costs, } 2015 \mathrm{CDN} \$ \\
\text { (Mean, } 95 \% \mathrm{Cl})\end{array}$ \\
\hline State 1 (no LN) & $1813(1034,2593)$ & $1797(995,2599)$ \\
\hline State $2 / 3$ (no LN) & $2955(37,5873)$ & $2740(1467,4013)$ \\
\hline State 1 (LN) & $3858(2858,4859)$ & $3768(2341,5194)$ \\
\hline State 2 (LN) & $4012(2362,5662)$ & $4739(3485,5993)$ \\
\hline State 3 (LN) & 20837 (3628, 38046) & $5643(3302,7984)$ \\
\hline ESRD & $51313(38645,63982)$ & $50944(38158,63730)$ \\
\hline
\end{tabular}

*eGFR: state $1>60 \mathrm{~mL} / \mathrm{min}$, state $230-60 \mathrm{~mL} / \mathrm{min}$, state $3<30 \mathrm{~mL} / \mathrm{min}$

ePrU: state $1<0.25 \mathrm{~g} / \mathrm{d}$, state $20.25-3.0 \mathrm{~g} / \mathrm{d}$, state $3>3.0 \mathrm{~g} / \mathrm{d}$

This article is protected by copyright. All rights reserved. 
Table 3 - Probabilities of transitioning between states and duration of eGFR and ePrU states over 1 year

\begin{tabular}{|c|c|c|c|c|c|c|}
\hline \multirow[b]{3}{*}{ Initial State* } & \multicolumn{6}{|c|}{ Probability of being in state after 1 year } \\
\hline & State 1 & State $2 / 3$ & State 1 & State 2 & State 3 & \\
\hline & no LN & no LN & $\mathrm{LN}$ & LN & LN & ESRD \\
\hline \multicolumn{7}{|l|}{ eGFR } \\
\hline State 1 (no LN) & 0.955 & 0.020 & 0.024 & 0.001 & 0.000 & 0.000 \\
\hline State 2/3 (no LN) & 0.364 & 0.598 & 0.011 & 0.025 & 0.002 & 0.000 \\
\hline State 1 (LN) & 0 & 0 & 0.957 & 0.039 & 0.003 & 0.001 \\
\hline State $2(\mathrm{LN})$ & 0 & 0 & 0.314 & 0.557 & 0.096 & 0.033 \\
\hline State $3(\mathrm{LN})$ & 0 & 0 & 0.040 & 0.146 & 0.438 & 0.376 \\
\hline ESRD & 0 & 0 & 0 & 0 & 0 & 1 \\
\hline \multicolumn{7}{|l|}{ ePrU } \\
\hline State 1 (no LN) & 0.931 & 0.050 & 0.012 & 0.006 & 0.001 & 0.000 \\
\hline State 2/3 (no LN) & 0.674 & 0.216 & 0.028 & 0.065 & 0.015 & 0.002 \\
\hline State $1(\mathrm{LN})$ & 0 & 0 & 0.814 & 0.171 & 0.011 & 0.004 \\
\hline State 2 (LN) & 0 & 0 & 0.354 & 0.567 & 0.063 & 0.016 \\
\hline State $3(\mathrm{LN})$ & 0 & 0 & 0.162 & 0.467 & 0.314 & 0.057 \\
\hline \multirow[t]{2}{*}{ ESRD } & 0 & 0 & 0 & 0 & 0 & 1 \\
\hline & \multicolumn{6}{|c|}{ Expected duration in state over 1 year } \\
\hline \multicolumn{7}{|l|}{ eGFR } \\
\hline State 1 (no LN) & 0.977 & 0.011 & 0.012 & 0.000 & 0.000 & 0.000 \\
\hline State $2 / 3$ (no LN) & 0.198 & 0.781 & 0.004 & 0.015 & 0.001 & 0.000 \\
\hline State $1(\mathrm{LN})$ & 0 & 0 & 0.977 & 0.022 & 0.001 & 0.000 \\
\hline State 2 (LN) & 0 & 0 & 0.173 & 0.752 & 0.062 & 0.012 \\
\hline State $3(\mathrm{LN})$ & 0 & 0 & 0.014 & 0.093 & 0.684 & 0.209 \\
\hline
\end{tabular}

This article is protected by copyright. All rights reserved. 


\begin{tabular}{|c|c|c|c|c|c|c|}
\hline ESRD & 0 & 0 & 0 & 0 & 0 & 1 \\
\hline \multicolumn{7}{|l|}{ ePrU } \\
\hline State 1 (no LN) & 0.960 & 0.032 & 0.006 & 0.002 & 0.000 & 0.000 \\
\hline State $2 / 3$ (no LN) & 0.434 & 0.499 & 0.011 & 0.044 & 0.010 & 0.001 \\
\hline State $1(\mathrm{LN})$ & 0 & 0 & 0.895 & 0.100 & 0.004 & 0.001 \\
\hline State $2(\mathrm{LN})$ & 0 & 0 & 0.206 & 0.743 & 0.043 & 0.008 \\
\hline State $3(\mathrm{LN})$ & 0 & 0 & 0.065 & 0.323 & 0.580 & 0.032 \\
\hline ESRD & 0 & 0 & 0 & 0 & 0 & 1 \\
\hline
\end{tabular}

*eGFR: state $1>60 \mathrm{~mL} / \mathrm{min}$, state $230-60 \mathrm{~mL} / \mathrm{min}$, state $3<30 \mathrm{~mL} / \mathrm{min}$

ePrU: state $1<0.25 \mathrm{~g} / \mathrm{d}$, state $20.25-3.0 \mathrm{~g} / \mathrm{d}$, state $3>3.0 \mathrm{~g} / \mathrm{d}$

This article is protected by copyright. All rights reserved. 
Table 4 - Predicted 5-year and 10-year cumulative health costs stratified by baseline state of renal function for eGFR and ePrU

\begin{tabular}{|c|c|c|}
\hline eGFR/ePrU State* & $\begin{array}{c}\text { eGFR } \\
\text { Costs, 2015 CDN\$ } \\
\text { (Mean, 95\% Cl) }\end{array}$ & $\begin{array}{c}\text { ePrU } \\
\text { Costs, 2015 CDN\$ } \\
\text { (Mean, } 95 \% \mathrm{Cl} \text { ) }\end{array}$ \\
\hline \multicolumn{3}{|l|}{5 -year } \\
\hline State 1 (no LN) & $9536(5246,13825)$ & $9651(5393,13909)$ \\
\hline State $2 / 3$ (no LN) & $12641(4340,20941)$ & $12317(7298,17336)$ \\
\hline State $1(\mathrm{LN})$ & $20829(14666,26992)$ & $22479(14924,30034)$ \\
\hline State 2 (LN) & $47486(30248,64723)$ & $27788(19339,36236)$ \\
\hline State 3 (LN) & $154320(100919,207721)$ & $39638(27834,51441)$ \\
\hline ESRD & $242196(182407,301985)$ & $240499(180173,300826)$ \\
\hline \multicolumn{3}{|l|}{ 10-year } \\
\hline State 1 (no LN) & $19987(11061,28913)$ & $20499(11681,29318)$ \\
\hline State 2/3 (no LN) & $25988(12175,39802)$ & $25997(15747,36247)$ \\
\hline State $1(\mathrm{LN})$ & $47524(33158,61891)$ & $50997(34654,67340)$ \\
\hline State 2 (LN) & $111326(76466,146185)$ & $61030(42667,79394)$ \\
\hline State $3(\mathrm{LN})$ & 310579 (217631, 403528) & $84040(59619,108461)$ \\
\hline ESRD & $451406(339977,562835)$ & $448336(335942,560730)$ \\
\hline \multicolumn{3}{|c|}{$\begin{array}{l}\text { eGFR = estimated glomerular filtration rate; } \mathrm{ePrU}=\text { estimated proteinuria; } \mathrm{ESRD}=\text { end-stage renal disease; } \mathrm{LN} \\
=\text { lupus nephritis; } \mathrm{CDN}=\text { Canadian }\end{array}$} \\
\hline
\end{tabular}

This article is protected by copyright. All rights reserved. 